\title{
Benzene Removal by Iron Oxide Nanoparticles Decorated Carbon Nanotubes
}

\author{
Aamir Abbas, ${ }^{1}$ Basim Ahmed Abussaud, ${ }^{1}$ Ihsanullah, ${ }^{1}$ Nadhir A. H. Al-Baghli, ${ }^{1}$ \\ Marwan Khraisheh, ${ }^{2}$ and Muataz Ali Atieh ${ }^{2,3}$ \\ ${ }^{1}$ Department of Chemical Engineering, King Fahd University of Petroleum \& Minerals, Dhahran 31261, Saudi Arabia \\ ${ }^{2}$ Qatar Environment and Energy Research Institute, Hamad Bin Khalifa University, Qatar Foundation, P.O. Box 5825, Doha, Qatar \\ ${ }^{3}$ College of Science and Engineering, Hamad Bin Khalifa University, Qatar Foundation, P.O. Box 5825, Doha, Qatar
}

Correspondence should be addressed to Basim Ahmed Abussaud; basim@kfupm.edu.sa and Muataz Ali Atieh; mhussien@qf.org.qa

Received 17 July 2015; Revised 22 November 2015; Accepted 24 November 2015

Academic Editor: Xie Quan

Copyright ( 2016 Aamir Abbas et al. This is an open access article distributed under the Creative Commons Attribution License, which permits unrestricted use, distribution, and reproduction in any medium, provided the original work is properly cited.

In this paper, carbon nanotubes (CNTs) impregnated with iron oxide nanoparticles were employed for the removal of benzene from water. The adsorbents were characterized using scanning electron microscope, X-ray diffraction, BET surface area, and thermogravimetric analysis. Batch adsorption experiments were carried out to study the adsorptive removal of benzene and the effect of parameters such as $\mathrm{pH}$, contact time, and adsorbent dosage. The maximum removal of benzene was $61 \%$ with iron oxide impregnated CNTs at an adsorbent dosage $100 \mathrm{mg}$, shaking speed $200 \mathrm{rpm}$, contact time 2 hours, initial concentration $1 \mathrm{ppm}$, and pH 6. However, raw CNTs showed only 53\% removal under same experimental conditions. Pseudo-first-order kinetic model was found well to describe the obtained data on benzene removal from water. Initial concentration was varied from 1 to $200 \mathrm{mg} / \mathrm{L}$ for isotherms study. Langmuir isotherm model was observed to best describe the adsorption data. The maximum adsorption capacities were $987.58 \mathrm{mg} / \mathrm{g}$ and $517.27 \mathrm{mg} / \mathrm{g}$ for iron oxide impregnated CNTs and raw CNTs, respectively. Experimental results revealed that impregnation with iron oxide nanoparticles significantly increased the removal efficiency of CNTs.

\section{Introduction}

Benzene is an aromatic compound which is natural part of petroleum fractions. It is widely used for many applications which include application as raw material for polymer and plastic industries and also as a solvent in paints industries [1-3]. Benzene is highly toxic and causes different diseases in humans such as cancer, central nervous system damage, and skin and eyes diseases [4]. Various methods have been reported for removal of this pollutant from water. Those methods include wet air oxidation [5], advanced oxidation process, photocatalytic degradation [6], and adsorption, which is considered as cheap and best practiced technique for removal of benzene [7].

Carbon nanotubes, since their discovery, by Iijima in 1991 [8], have shown a great potential in many areas especially in water treatment. CNTs attained great attention due to better electrical, chemical, and mechanical properties as compared to other adsorbents such as fly ash and activated carbon $[9,10]$. Carbon nanotubes are $\mathrm{sp}^{2}$ hybridized graphitic carbon sheets, folded in the form of hollow cylinders. These materials contain localized $\pi$-electrons on their surface which make them better adsorbents for removal of contaminants as compared to conventional adsorbent, activated carbon $[11,12]$.

Different adsorbents have been used for the removal of benzene, toluene, ethylbenzene, and xylene isomers (BTEX) from water. The most common materials reported are activated carbon [4], raw carbon nanotubes [13], and modified carbon nanotubes [14-16] for removal of BTEX. Recently, metal oxide impregnated CNTs have shown better adsorption capacity and removal efficiency as compared to raw CNTs and other adsorbents for different pollutants [17-22]. Novel carbon nanotube membranes are also appealing candidates for a number of applications in water treatment $[23,24]$.

According to our knowledge, not even a single publication was found to study the removal of benzene using metal oxide impregnated CNTs. Based on this, objective 
of this study was to prepare and characterize iron oxide nanoparticles impregnated multiwall carbon nanotubes and to demonstrate the utilization for adsorption of benzene from water.

\section{Materials and Experimental Setup}

2.1. Materials. Commercial multiwall carbon nanotubes were purchased from Chengdu Organic Chemicals Co. Ltd. (China) with purity of greater than $95 \%$. Other chemicals which include iron nitrate, ethanol, benzene ( $99.7 \%$ purity), nitric acid (>69\% purity), and sodium hydroxide were purchased from Sigma Aldrich.

2.1.1. CNTs Impregnation with Iron Oxide Nanoparticles. The carbon nanotubes purchased were 10-30 micrometers in length, 10-20 nanometers in outer diameters, and having specific surface area of $>200 \mathrm{~m}^{2} / \mathrm{g}$. For impregnation of iron oxide nanoparticles on CNTs, $20 \mathrm{~g}$ of CNTs (90\% of total weight of CNTs and metallic salt) was weighed and dissolved in sufficient amount of ethanol. CNTs dissolved in ethanol were ultrasonicated for 30 minutes, to deagglomerate and disperse CNTs in the solvent. $2 \mathrm{~g}$ of iron nitrate salt $(10 \%$ of total weight of CNTs and metallic salt) was dissolved in sufficient amount of ethanol, mixed with CNTs, and sonicated further for 30 minutes. Sample was dried in oven at $80^{\circ} \mathrm{C}$. After complete drying of ethanol, the sample was calcined in a furnace at $350^{\circ} \mathrm{C}$ for 4 hours.

2.2. Characterization of Adsorbents. The adsorbents were analyzed using various characterization techniques. Physical morphology and structure analysis was carried out using scanning electron microscope (SEM Model, TESCAN MIRA 3 FEG-SEM). Energy dispersive X-ray (TESCAN MIRA 3 FEG-SEM) was also performed to verify the presence of different elements in prepared adsorbents. The samples were coated with a Platinum layer of $5 \mathrm{~nm}$ thickness (Quorum sputter coater model: Q150R S). X-ray dispersive (XRD) spectroscopy was performed to confirm the presence of CNTs and iron oxide. The XRD patterns were recorded using an $\mathrm{X}$-ray diffractometer (model: Bruker D8 Advance), equipped with $\mathrm{Cu} \mathrm{K}$ radiation source $(40 \mathrm{kV}, 20 \mathrm{~mA})$ at a rate of $1.0^{\circ} / \mathrm{min}$ over the $2 \theta$ range of $10-100^{\circ}$. Surface area of both raw and iron oxide impregnated CNTs was analyzed using BET surface area analyzer (model: Micromeritics ASAP 2020 Instrument). Thermogravimetric analysis (TGA) was carried out using TGA equipment (model: SDT Q600 TA Instrument) to check the residual weight and thermal degradation of carbon nanotubes.

2.3. Batch Adsorption. For batch adsorption experiments, stock solution of benzene with the concentration of $100 \mathrm{ppm}$ was prepared and diluted to get $1 \mathrm{ppm}$ concentration. Glass flasks containing adsorbents were filled completely with benzene solution and were mounted on mechanical shaker (Lab Companion Model: SK-600) for specific time at room temperature. After completion of provided contact time, samples were removed from shaker and filtered using Whatman
Filter Paper number 1 of $11 \mu \mathrm{m}$ pore size to collect sample for analysis of benzene concentration. To study the effect of $\mathrm{pH}$ on the adsorption of benzene, $\mathrm{pH}$ of the solution was varied from 5 to 8 by using $1 \mathrm{M}$ solution of nitric acid and $1 \mathrm{M}$ solution of sodium hydroxide.

The adsorption capacity of benzene on CNTs surface was calculated using

$$
q=\frac{\left(C_{0}-C\right)}{m} * V,
$$

where $q$ is adsorption capacity $(\mathrm{mg} / \mathrm{g}), C_{0}$ is initial concentration of benzene in sample $(\mathrm{mg} / \mathrm{L}), C$ is final concentration of benzene in sample at time $t(\mathrm{mg} / \mathrm{L}), V$ is volume of sample $(\mathrm{mL})$, and $m$ is amount of adsorbent $(\mathrm{g})$.

Percentage removal was found using the following equation:

$$
\text { Removal }(\%)=\frac{C_{0}-C}{C_{0}} * 100 .
$$

In order to avoid any losses due to volatilization during experimentation, benzene solution was filled completely in flasks and no headspace was left. Control experiments were conducted without adding any adsorbent to check the adsorption of benzene on surface of glass flasks and loss due to volatilization.

Most widely used kinetics models for adsorption are pseudo-first-order model and pseudo-second-order model [25]. Pseudo-first-order model of Lagergren is provided by

$$
\log \left(q_{e}-q\right)=\log \left(q_{e}\right)-\frac{k_{1} t}{2.303}
$$

where $q_{e}$ and $q$ indicate the amount of benzene $(\mathrm{mg} / \mathrm{g})$ adsorbed at equilibrium and various time " $t$," respectively, and $k_{1}\left(\mathrm{~min}^{-1}\right)$ is the rate constant of this model. In order to determine the values of $k_{1}$ and $q_{e}$ linear plot of $\log \left(q_{e}-q\right)$ and " $t$ " was used $[25,26]$.

The linear form of pseudo second order is given as

$$
\frac{t}{q}=\frac{1}{k_{2} q_{e}^{2}}+\frac{t}{q_{e}},
$$

where $q_{e}$ and $q$ are the amount of benzene adsorbed (mg/g) on the surface of CNTs at equilibrium and various time " $t$," respectively. $k_{2}(\mathrm{~g} /(\mathrm{mg} \mathrm{min}))$ is the rate constant for pseudosecond-order kinetic model. The values of $q_{e}$ and $k_{2}$ can be determined from slope and intercept of linear plot of $t / q$ versus $t[16,27]$.

In order to get more information for internal diffusion inside adsorbent, intraparticle diffusion model was also used. Linear form of intraparticle diffusion model is provided in

$$
q_{t}=k_{\mathrm{id}} t^{0.5}+C
$$

where $k_{\mathrm{id}}$ is intraparticle diffusion rate constant with units as $\mathrm{mg} / \mathrm{g} \mathrm{min}^{-0.5}$ and $C(\mathrm{mg} / \mathrm{g})$ is intercept which can be calculated by plotting $q_{t}$ versus $t^{0.5}$.

Adsorption isotherms are most important in order to understand the adsorption mechanism and also to determine the amount of adsorbent needed to adsorb a specific 


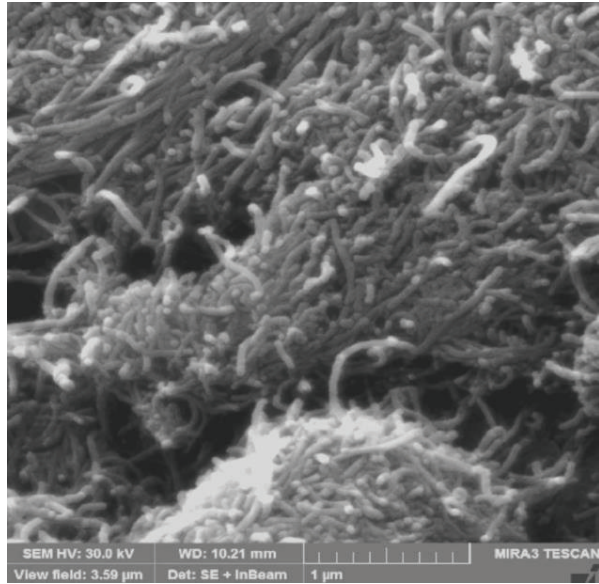

(a)

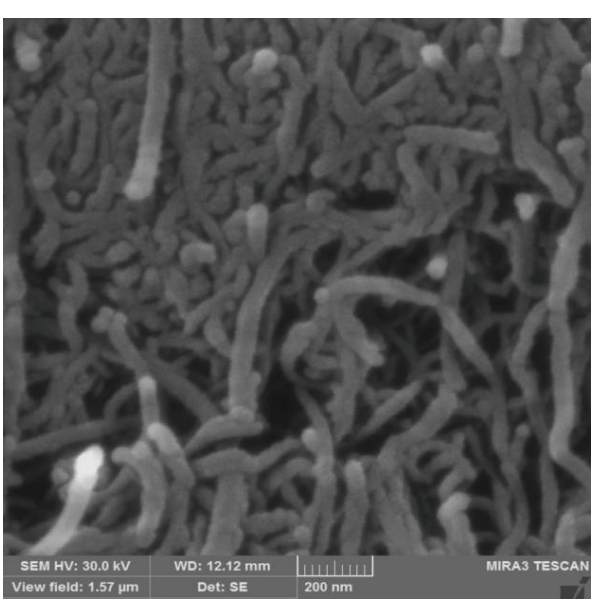

(b)

FIGURE 1: SEM images of (a) low magnification and (b) high magnification of CNTs.

amount of adsorbate. For this purpose Langmuir, Freundlich, and Dubinin-Radushkevich (D-R) isotherm models were employed to fit the experimental data [28-30]. Representative equations of Langmuir and Freundlich models are provided as

$$
\begin{aligned}
& q_{e}=\frac{K_{L} q_{m} C_{e}}{1+K_{L} C_{e}}, \\
& q_{e}=K_{F} C_{e}^{1 / n},
\end{aligned}
$$

where $q_{e}$ represents the concentration of adsorbate on the surface of adsorbent and $C_{e}$ indicates the concentration of adsorbate in water when equilibrium was reached. $q_{m}$ is the maximum adsorption capacity and $K_{L}$ is the Langmuir adsorption equilibrium constant $(\mathrm{L} / \mathrm{mg}) . K_{F}$ is Freundlich constant related to adsorption capacity with units $(\mathrm{mg} / \mathrm{g})$ $(\mathrm{L} / \mathrm{mg})^{1 / n}$ and " $n$ " is Freundlich constant related to adsorption intensity of the adsorbents; it is dimensionless.

$\mathrm{D}-\mathrm{R}$ model was used to have an idea about physical or chemical adsorption of benzene molecules with CNTs surface. Equation of D-R model is as follows:

$$
q_{e}=q_{m} e^{-B \varepsilon^{2}} \text {. }
$$

Here, $B\left(\right.$ moles $\left.^{2} / \mathrm{kJ}^{2}\right)$ is related to mean free energy of adsorption and $q_{m}(\mathrm{mg} / \mathrm{g})$ is saturation capacity. $\varepsilon$ is Polanyi potential and is calculated as

$$
\varepsilon=R T \ln \left(1+\frac{1}{C_{e}}\right),
$$

where $R(\mathrm{~kJ} / \mathrm{mole} / \mathrm{K})$ is the gas constant and $T(\mathrm{~K})$ is absolute temperature. Mean free energy of adsorption $\left(E_{a}\right)$ for one mole of adsorbate, by moving from infinity to adsorption site, is calculated as follows:

$$
E_{a}=\frac{1}{(2 B)^{0.5}} .
$$

In order to avoid the error occurring due to use of linearized form of models, nonlinear regression analysis was performed for all models using Mathematica 9.0.
2.4. Benzene Concentration Analysis. The concentration of benzene solution was determined using gas chromatograph mass spectrometer (GC 7890A and MS 5975C, Agilent Inc., USA). GC-MS headspace auto-multisampler was used for sample injection.

The capillary column (DB-1) was used with specification of $30 \mathrm{~m}$ length, $320 \mu \mathrm{m}$ inner diameter (ID), and $1 \mu \mathrm{m}$ column width. Split mode was used for sample injection with $50: 1$ and volume of sample injected was $1000 \mu \mathrm{L}$. The temperature of oven was $40^{\circ} \mathrm{C}$ and later raised to $180^{\circ} \mathrm{C}$ with the rate of $35^{\circ} \mathrm{C}$ per minute, injection inlet temperature was $200^{\circ} \mathrm{C}$, and auxiliary temperature was $280^{\circ} \mathrm{C}$, while syringe temperature used was $100^{\circ} \mathrm{C}$.

\section{Characterization of Raw and Impregnated CNTs}

Figures 1(a) and 1(b) display the SEM images of low and high magnifications of raw carbon nanotubes. The diameters of the CNTs were varying from 10 to $20 \mathrm{~nm}$ with an average diameter of $14 \mathrm{~nm}$, while the length of these carbon nanotubes was varying from 10 to $30 \mu \mathrm{m}$. This study was also supported by the characterization of doped CNTs with iron oxide nanoparticles using backscattering SEM in order to verify the presence of nanoparticles on the surfaces of the CNTs as shown in Figures 2(a) and 2(b). The backscattering images were taken for two different samples at 1 and $10 \mathrm{wt} \%$ of $\mathrm{Fe}_{2} \mathrm{O}_{3}$ nanoparticles doped on CNTs. It was observed that there are many formations of white crystal structures of $\mathrm{Fe}_{2} \mathrm{O}_{3}$ nanoparticles with small sizes and irregular shapes. The distribution and agglomeration of $\mathrm{Fe}_{2} \mathrm{O}_{3}$ nanoparticles were also observed. At low concentration of $\mathrm{Fe}_{2} \mathrm{O}_{3}$ nanoparticles $(1 \mathrm{wt} . \%)$, the particles spread widely on the surfaces of carbon nanotubes forming very small crystals particles with diameters varying from 1 to $5 \mathrm{~nm}$, while at high concentration of $\mathrm{Fe}_{2} \mathrm{O}_{3}$ nanoparticles (10 wt.\%) the particles were agglomerating forming big crystals nanoparticles with diameters varying from 1 to $15 \mathrm{~nm}$. 


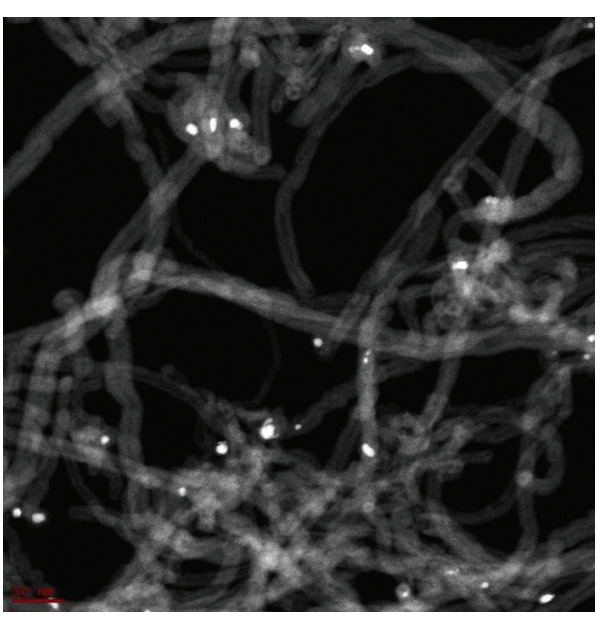

(a)

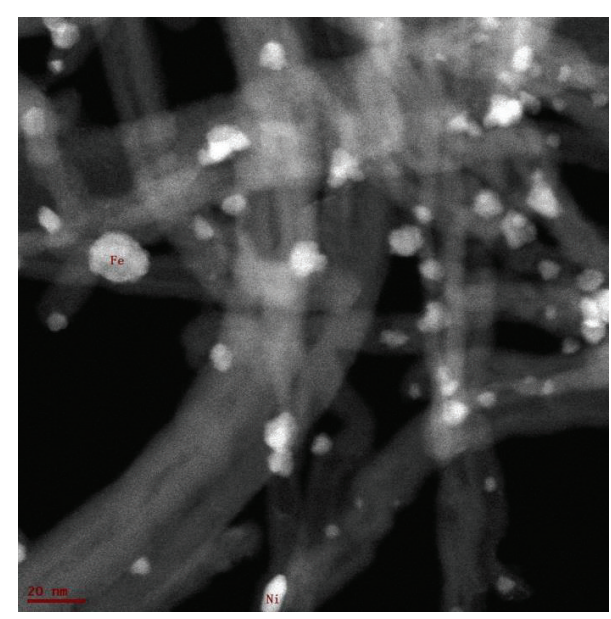

(b)

FIGURE 2: Backscattering SEM images for (a) $1 \mathrm{wt} . \%$ and $10 \mathrm{wt} . \%$ of iron oxide nanoparticles impregnated on the surface of CNTs.

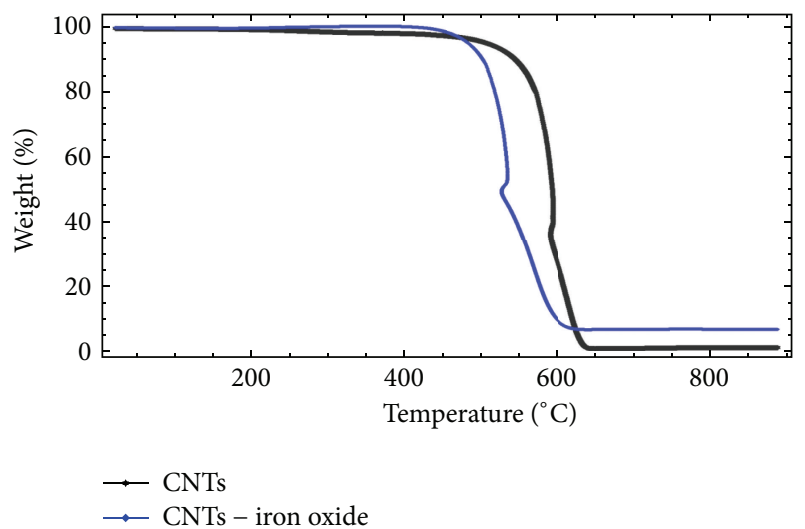

Figure 3: TGA curves for raw CNTs and iron oxide nanoparticles impregnated CNTs.

Figure 3 demonstrates the thermogravimetric behavior of both raw and iron oxide nanoparticles impregnated CNTs. It can be observed that the raw CNTs are more stable and thermal degradation takes place at around $530^{\circ} \mathrm{C}$. Impregnation of CNTs with iron oxide nanoparticles increased the destabilization in CNTs and degradation started at lower temperature, $450^{\circ} \mathrm{C}$ [31]. The reason behind this phenomenon may be due to high thermal conductivity of iron oxide nanoparticle heating rate in sample enhanced, hence leading to fast degradation of CNTs. The mass left over the pan after burning of raw CNTs represents the catalyst particles, which was found to be nickel as confirmed from EDX analysis. It is also observed that the residual mass was high (about 7\%) for iron oxide impregnated CNTs and it represented the metal oxide nanoparticle impregnated on CNTs.

Figures 4 and 5 demonstrate the nitrogen adsorption desorption isotherms for both raw CNTs and iron oxide impregnated CNTs, respectively. Isotherm was found to be of type $\mathrm{V}$, according to International Union of Pure

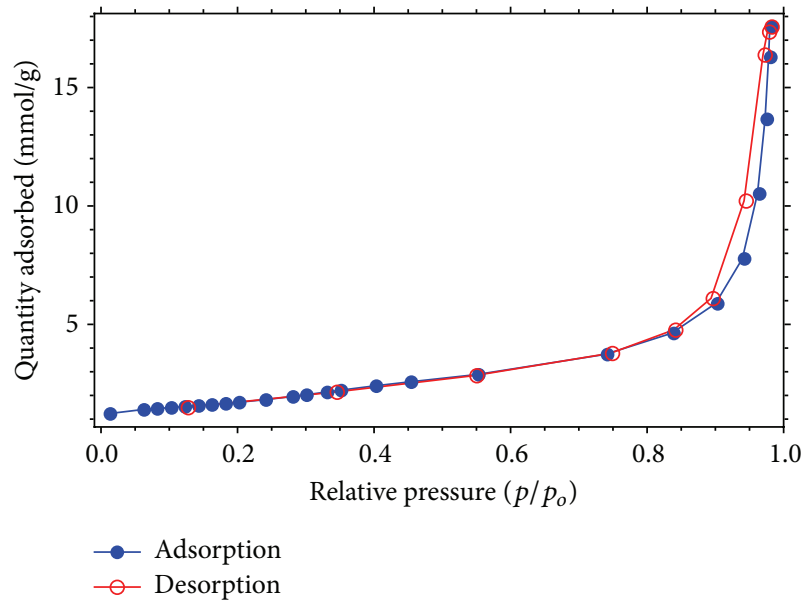

FIGURE 4: Nitrogen adsorption desorption isotherms for raw CNTs.

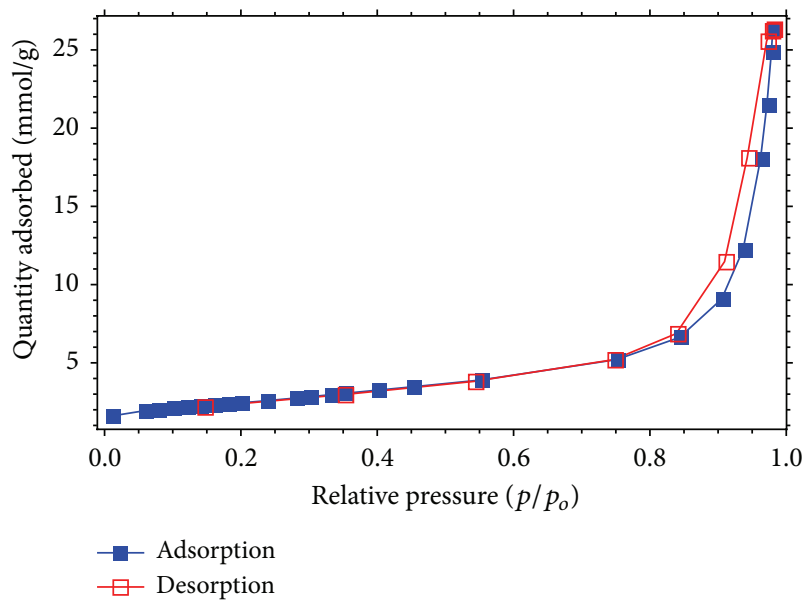

FIGURE 5: Nitrogen adsorption desorption isotherms for iron oxide impregnated CNTs. 

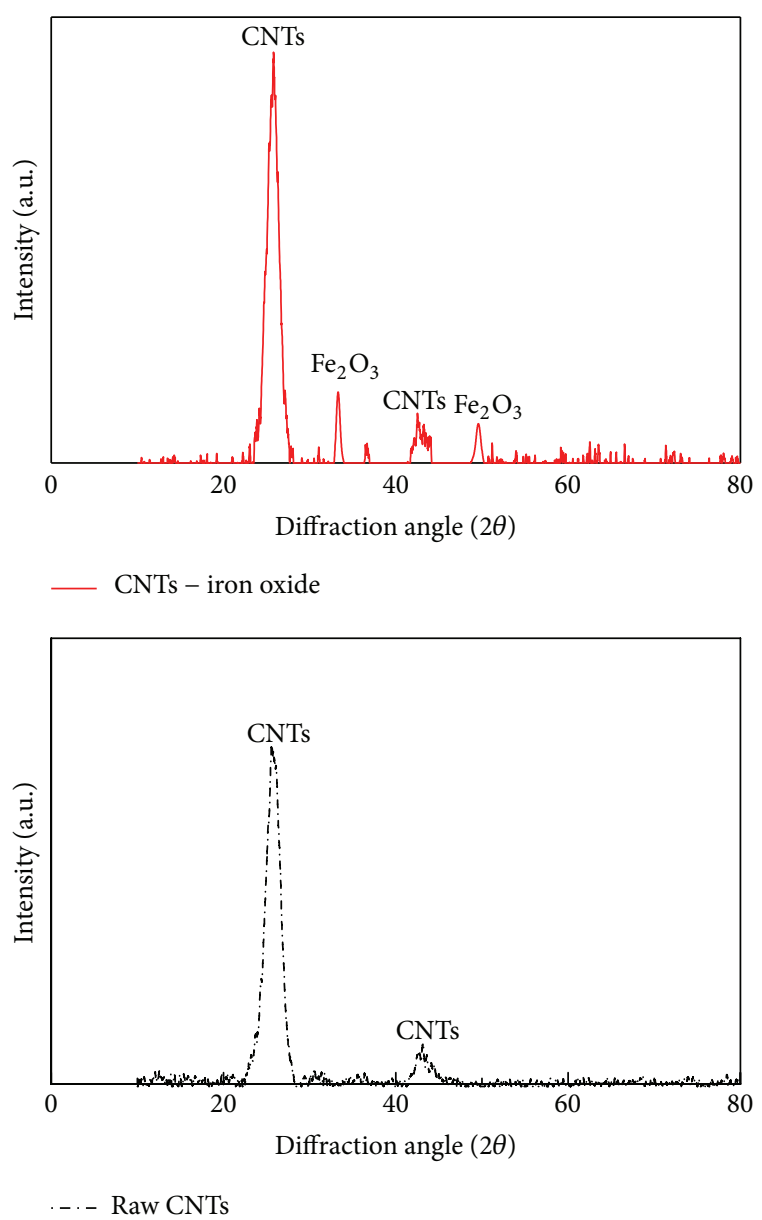

FIGURE 6: XRD analysis of raw CNTs and iron oxide nanoparticles impregnated CNTs.

and Applied Chemistry (IUPAC) classification of adsorption isotherm, which represents the monolayer adsorption. Hysteresis between adsorption desorption isotherms was due to capillary condensation. BET surface area was calculated using BET equation and was found to be as $155 \mathrm{~m}^{2} / \mathrm{g}$ for raw CNTs and $210 \mathrm{~m}^{2} / \mathrm{g}$ for iron oxide impregnated CNTs. This indicates that after impregnation the surface area of functionalized CNTs increased due to iron oxide nanoparticles attachment on the surface of CNTs. Nitrogen adsorption desorption isotherms were found to be of type $\mathrm{V}$ which is indication of the adsorption of liquid nitrogen molecules on the external surface and inside mesopores of materials. Increase in surface area may be attributed to increase in dispersion of CNTs, hence providing more external adsorption sites.

Figure 6 shows the XRD pattern of raw CNTs and iron oxide impregnated CNTs. X-ray diffraction peaks at $2 \theta$ of $26.1^{\circ}$ and $43.2^{\circ}$ correspond to graphitic structure of CNTs in both samples $[14,32,33]$. Both raw and iron oxide impregnated CNTs contain same structure of carbon in the sample. Similarly, presence of iron oxide can be observed from peaks at $2 \theta$ of $35^{\circ}, 44^{\circ}$, and $52^{\circ}[34-36]$.

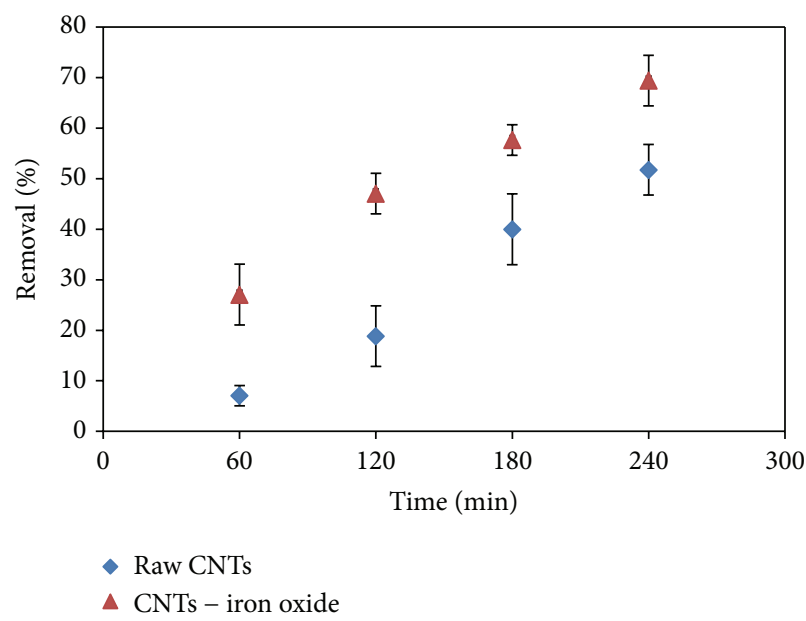

FIgURE 7: Effect of contact time on benzene removal using raw CNTs and iron oxide impregnated CNTs (initial concentration: $1 \mathrm{mg} / \mathrm{L}$, adsorbent dosage: $50 \mathrm{mg}$, shaking speed: $200 \mathrm{rpm}, \mathrm{pH}$ : 6; and temperature: $298 \mathrm{~K}$ ).

\section{Adsorption Experiments}

Batch adsorption experiments were carried out to study the effect of contact time, sorbent dosage, and $\mathrm{pH}$ of the solution on the benzene sorption.

4.1. Effect of Contact Time. The effect of contact time on benzene adsorption was carried out by varying the time from 60 minutes to 240 minutes. Figure 7 reveals the effect of contact time on removal efficiency and adsorption capacity of raw CNTs and iron oxide nanoparticles impregnated CNTs. Maximum removal achieved was $51 \%$, while maximum adsorption capacity was $1.14 \mathrm{mg} / \mathrm{g}$ with raw CNTs. By impregnating CNTs with iron oxide nanoparticles, removal efficiency and adsorption capacity both increased, maximum removal was $70 \%$, and adsorption capacity enhanced to $1.54 \mathrm{mg} / \mathrm{g}$. The enhancement in removal efficiency of impregnated CNTs was due to the increase in the surface area from $155 \mathrm{~m}^{2} / \mathrm{g}$ to $210 \mathrm{~m}^{2} / \mathrm{g}$. The increase in surface area resulted in increase in the number of sorption sites on the surfaces of CNTs. It can also be observed that, by increasing the time, the adsorption capacity and percentage removal were increased for both raw and impregnated CNTs. This might be due to the attachment of more molecules on the available active $\pi-\pi$ sorption sites after long contact time.

4.2. Effect of Adsorbent Dosage. The impact of adsorbent dosage on adsorption capacity and percentage removal was analyzed using different amount of adsorbents ( 25 to $100 \mathrm{mg}$ ). Figure 8 represents the effect of adsorbent dosage on removal efficiency and adsorption capacity of raw CNTs and CNTs impregnated with iron oxide nanoparticles, respectively. It was observed that, with increase in the adsorbent dosage, the adsorption efficiency has increased. This can be justified due to the availability of more active adsorption sites at higher adsorbent dosage $[17,26]$. 


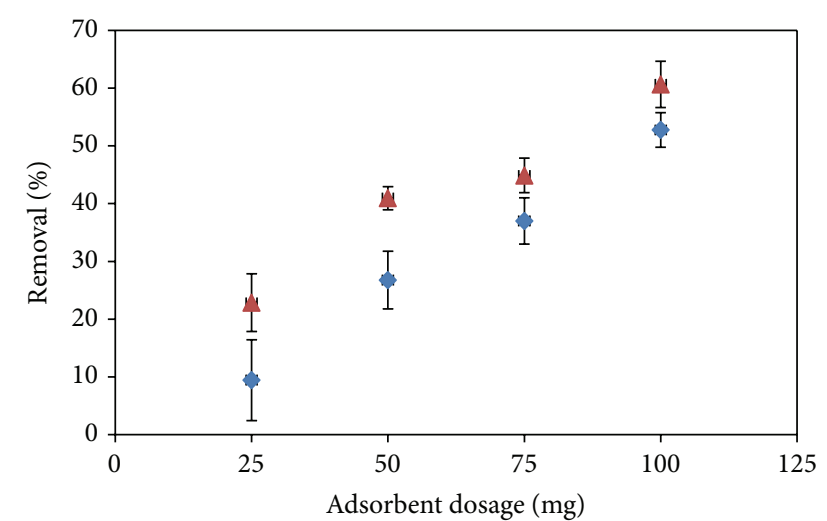

- Raw CNTs

- CNTs - iron oxide

FIGURE 8: Effect of dosage of raw CNTs and iron oxide nanoparticles impregnated CNTs on benzene removal (initial concentration: $1 \mathrm{mg} / \mathrm{L}$, contact time: $120 \mathrm{~min}$, shaking speed: $200 \mathrm{rpm}, \mathrm{pH}$ : 6; and temperature: $298 \mathrm{~K}$ ).

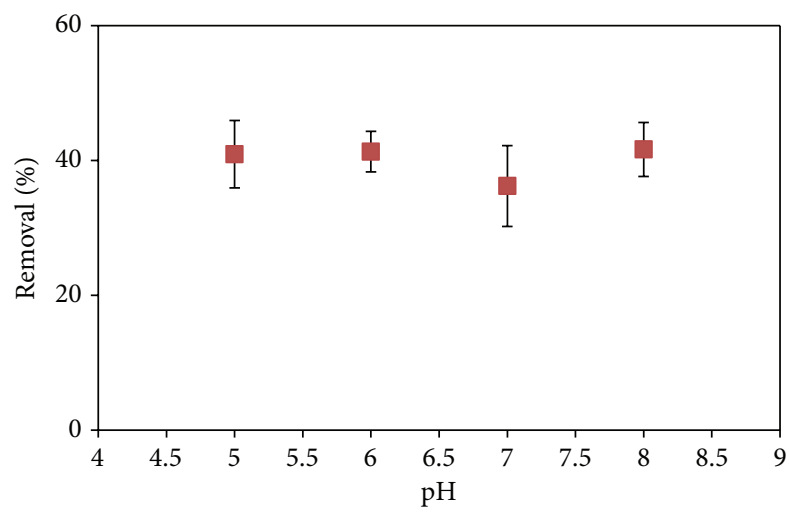

- CNTs - iron oxide

FIGURE 9: Effect of initial $\mathrm{pH}$ on benzene removal using iron oxide impregnated CNTs (initial concentration: $1 \mathrm{mg} / \mathrm{L}$, adsorbent dosage: $50 \mathrm{mg}$, contact time: $120 \mathrm{~min}$, shaking speed: $200 \mathrm{rpm}$, and temperature: $298 \mathrm{~K}$ ).

4.3. Effect of Solution $p H$. Figure 9 represents the $\mathrm{pH}$ effect on removal efficiency and adsorption capacity of iron oxide nanoparticles impregnated CNTs. $\mathrm{pH}$ of the solution was varied in the range of 5 to 8 , which is a typical $\mathrm{pH}$ range for mostly industrial water. It was observed that the removal efficiency was almost constant in this $\mathrm{pH}$ range. Since benzene exists in the molecular form at whole range of $\mathrm{pH}$, in this case dispersive interactions due to $\pi-\pi$ bond interaction were dominant in the removal of benzene from water. This is also in agreement with the existing literature [4].

\section{Adsorption Kinetics Analysis}

Figure 10 represents the adsorption capacity of the adsorbent versus time, for the removal of benzene. It was observed that the adsorption capacity increases almost linearly with

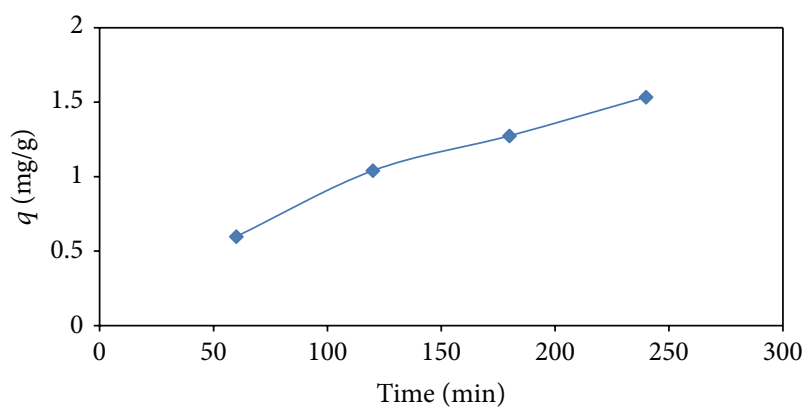

FIgURE 10: Adsorption capacity versus time plot for benzene adsorption.

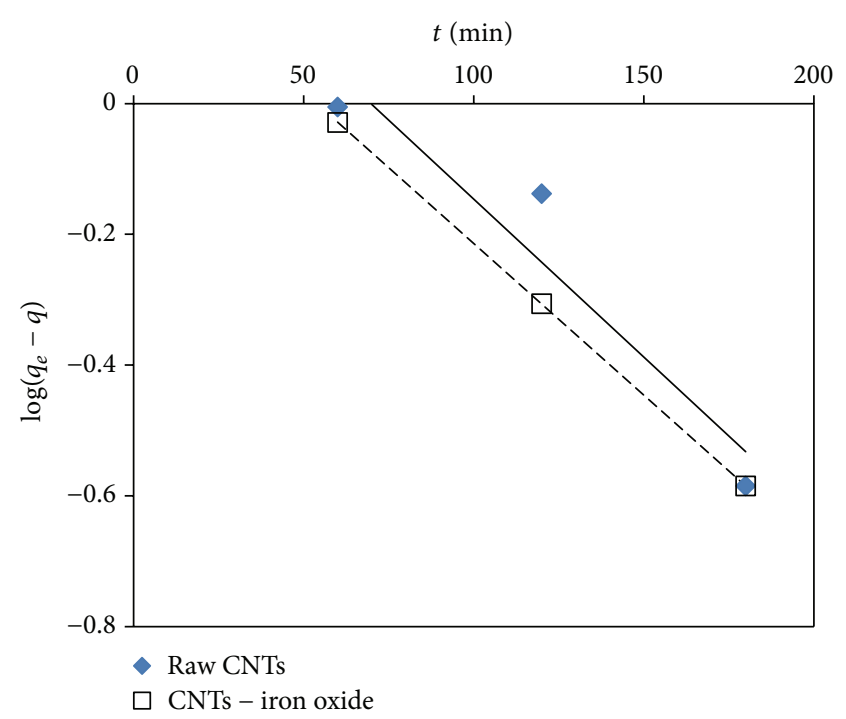

FIGURE 11: Adsorption kinetics pseudo-first-order model fitting with experimental data.

increase in time. This might be due to the attachment of more molecules on the available active $\pi-\pi$ sorption sites after long contact time.

In order to further investigate the adsorption phenomena, kinetics studies with pseudo-first-order model, pseudosecond-order model, and intraparticle diffusion model were conducted. As shown in Figures 11, 12, and 13, three kinetics models were employed to fit the experimental data of benzene adsorption from water. Kinetics parameters and determination coefficients $\left(R^{2}\right)$ of these models are provided in Table 1. It is evident from the values of determination coefficient $\left(R^{2}\right)$ that all models have good fit with experimental data. Pseudo-first-order model was found to best describe the adsorption of benzene on both raw and impregnated CNTs [16]. Besides, intraparticle diffusion model was also the best to describe the adsorption kinetics but plot of $q_{t}$ versus $t^{0.5}$ does not pass through the origin so it is not rate limiting step. Generally adsorption phenomenon occurs in three steps. In the first step, external diffusion occurs in which adsorbate molecule moves from bulk solution to the external surface of the adsorbent; in the second step, internal diffusion occurs in which adsorbate molecules move deep inside adsorbent 
TABLE 1: Kinetic parameters for benzene adsorbed on iron oxide nanoparticles impregnated CNTs.

\begin{tabular}{|c|c|c|c|}
\hline \multirow{2}{*}{ Model } & \multirow{2}{*}{ Parameters } & \multicolumn{2}{|c|}{ Adsorbents } \\
\hline & & Raw CNTs & CNTs - iron oxide \\
\hline \multirow{2}{*}{ Experimental } & $C_{0}(\mathrm{mg} / \mathrm{L})$ & 0.85 & 0.85 \\
\hline & $q_{e, \text { experimental }}$ & 1.14 & 1.534 \\
\hline \multirow{3}{*}{ Pseudo first order } & $k_{1}\left(\min ^{-1}\right)$ & 0.0048 & 0.0046 \\
\hline & $q_{e, \text { calculated }}$ & 2.1732 & 1.777 \\
\hline & $R^{2}$ & 0.9107 & 1.00 \\
\hline \multirow{3}{*}{ Pseudo second order } & $k_{2}\left(\mathrm{~g} \mathrm{mg}^{-1} \mathrm{~min}^{-1}\right)$ & $2.854 E-07$ & $1.31 E-03$ \\
\hline & $q_{e, \text { calculated }}$ & 90.90 & 3.088 \\
\hline & $R^{2}$ & 0.8635 & 0.9878 \\
\hline \multirow{3}{*}{ Intraparticle diffusion model } & $k_{\text {id }}\left(\mathrm{g} \mathrm{mg}^{-1} \min ^{-0.5}\right)$ & 0.132 & 0.1198 \\
\hline & C & -0.9212 & -0.3034 \\
\hline & $R^{2}$ & 0.9725 & 0.9949 \\
\hline
\end{tabular}

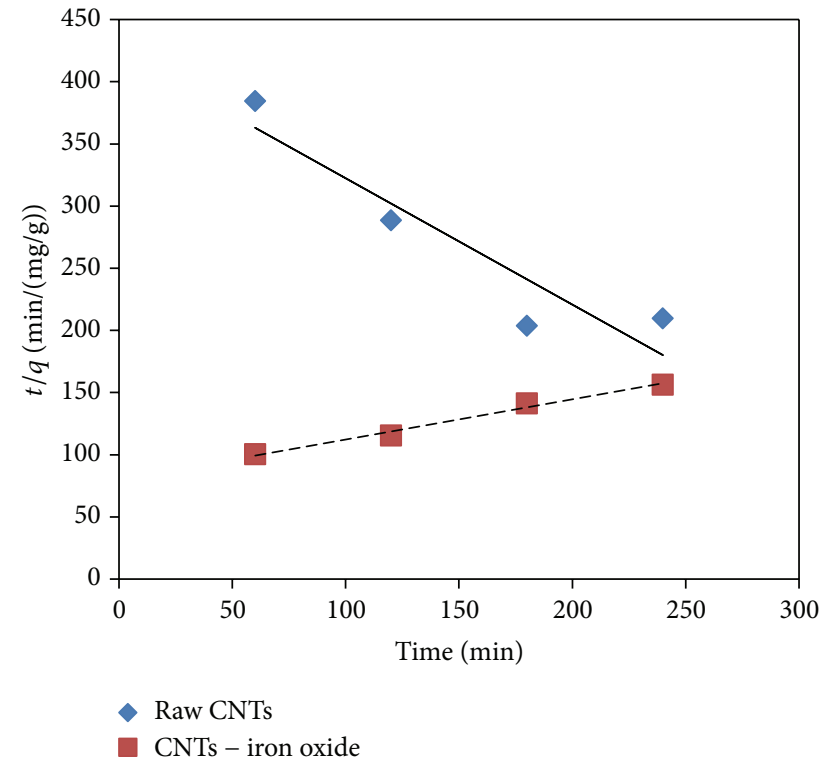

FIGURE 12: Adsorption kinetics pseudo-second-order model fitting with experimental data.

to active adsorption site; and in the last step, adsorbate is adsorbed on adsorption site, which is fast and negligible step [16].

\section{Adsorption Isotherms}

Figures 14, 15, and 16 represent the fitting of adsorption data with adsorption isotherm models for both raw and impregnated CNTs. Theoretical results of parameters and determination coefficient values are provided in Table 2. It can be seen from values of $R^{2}$ in Table 2 that all models fitted well with adsorption data but Langmuir model was best to represent the data. Values of dimensionless equilibrium parameter for Langmuir isotherm $\left(R_{L}\right)$ were found to be as 0.969 and 0.986 for raw CNTs and iron oxide impregnated CNTs, which indicates the favorable adsorption of benzene on these adsorbents. Adsorption capacity was higher for

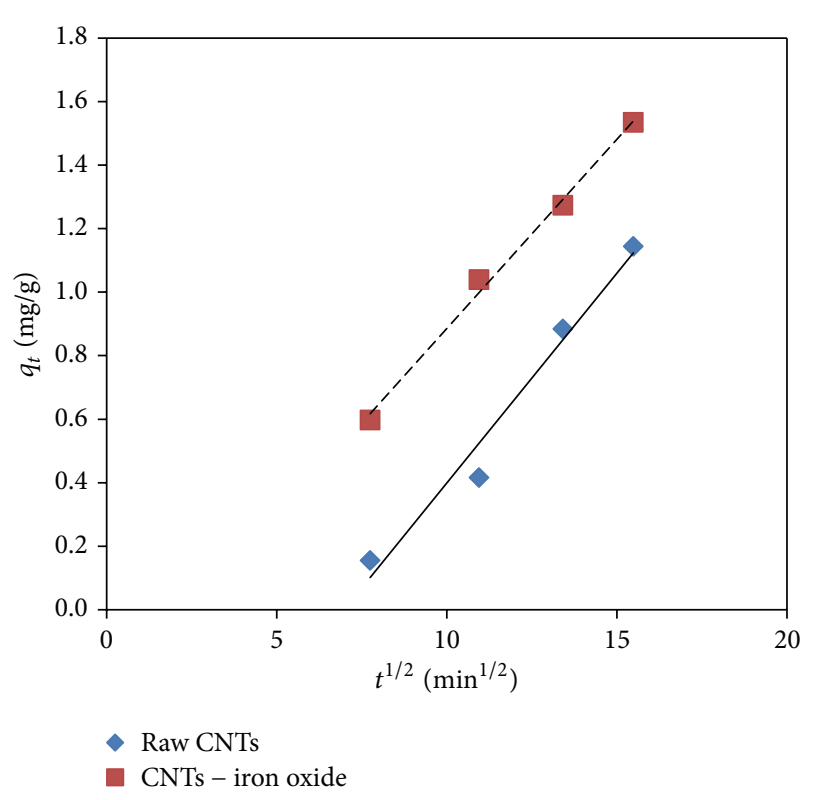

FIGURE 13: Adsorption kinetics intraparticle diffusion model fitting with experimental data.

impregnated CNTs as compared to raw CNTs which may be due to more dispersion and surface area available for adsorption of benzene molecules.

$\mathrm{D}-\mathrm{R}$ model was used to predict the energy of adsorption. Value of $E_{a}$ can provide information about adsorption mechanism. When 1 mole of a material is transferred to adsorption site, value between 1 and $8 \mathrm{~kJ} / \mathrm{mole}$ indicates physical adsorption, value between 8 and $16 \mathrm{~kJ} /$ mole shows adsorption due to ion exchange, and the value between 20 and $40 \mathrm{~kJ} /$ mole provides indication of chemisorption $[29,30]$. From Table 2, values of adsorption energy are $0.027 \mathrm{~kJ} / \mathrm{mole}$ for raw CNTs and $0.021 \mathrm{~kJ} /$ mole for iron oxide impregnated CNTs, indicating physical adsorption of benzene.

Main forces mainly involved in adsorption of organics on CNTs surface are hydrophobic effects, $\pi-\pi$ stacking, hydrogen covalent interactions, and Vander Waals forces [37, 
TABLE 2: Isotherm models parameters for benzene adsorbed on raw and iron oxide nanoparticles impregnated CNTs (pH: 6, temperature: $298 \mathrm{~K}$, and initial concentration: 1-200 mg/L).

\begin{tabular}{|c|c|c|c|}
\hline \multirow{2}{*}{ Model } & \multirow{2}{*}{ Parameters } & \multicolumn{2}{|c|}{ Adsorbents } \\
\hline & & Raw CNTs & CNTs - iron oxide \\
\hline \multirow{4}{*}{ Langmuir } & $K_{L}(\mathrm{~L} / \mathrm{mg})$ & 0.0031 & 0.0014 \\
\hline & $q_{m}(\mathrm{mg} / \mathrm{g})$ & 517.27 & 987.58 \\
\hline & $R^{2}$ & 0.992 & 0.994 \\
\hline & $R_{L}$ & 0.969 & 0.986 \\
\hline \multirow{3}{*}{ Freundlich } & $K_{F}(\mathrm{~L} / \mathrm{mg})$ & 3.027 & 1.926 \\
\hline & $n$ & 1.264 & 1.119 \\
\hline & $R^{2}$ & 0.989 & 0.993 \\
\hline \multirow{4}{*}{ Dubinin-Radushkevich (D-R) } & $q_{m}(\mathrm{mg} / \mathrm{g})$ & 207.21 & 248.45 \\
\hline & $B\left(\right.$ mole $\left.^{2} / \mathrm{kJ}^{2}\right)$ & 671.45 & 1136.23 \\
\hline & $E_{a}(\mathrm{~kJ} / \mathrm{mole})$ & 0.027 & 0.021 \\
\hline & $R^{2}$ & 0.993 & 0.994 \\
\hline
\end{tabular}

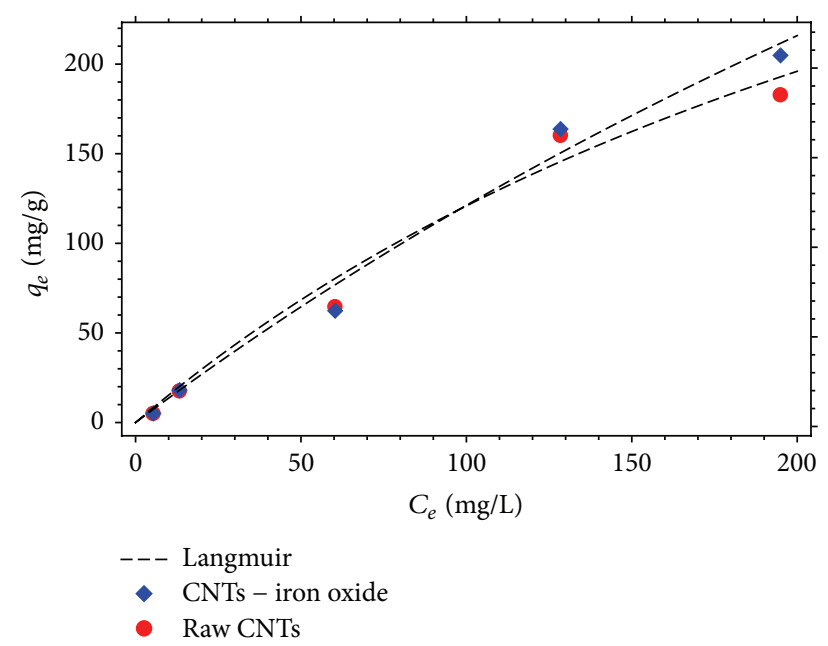

FIGURE 14: Langmuir adsorption isotherm model fitting with benzene adsorption on raw CNTs and iron oxide impregnated CNTs.

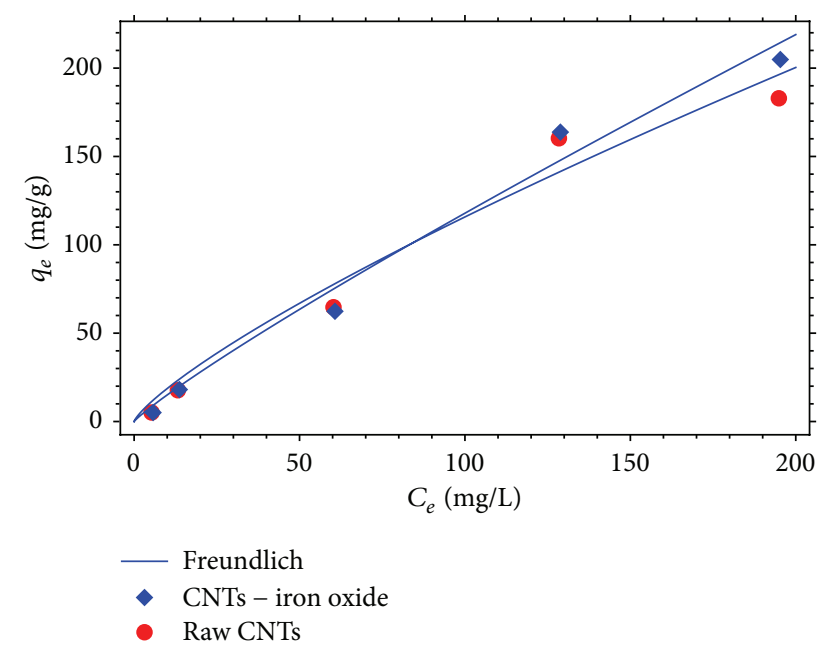

FIGURE 15: Freundlich adsorption isotherm model fitting with benzene adsorption on raw CNTs and iron oxide impregnated CNTs.

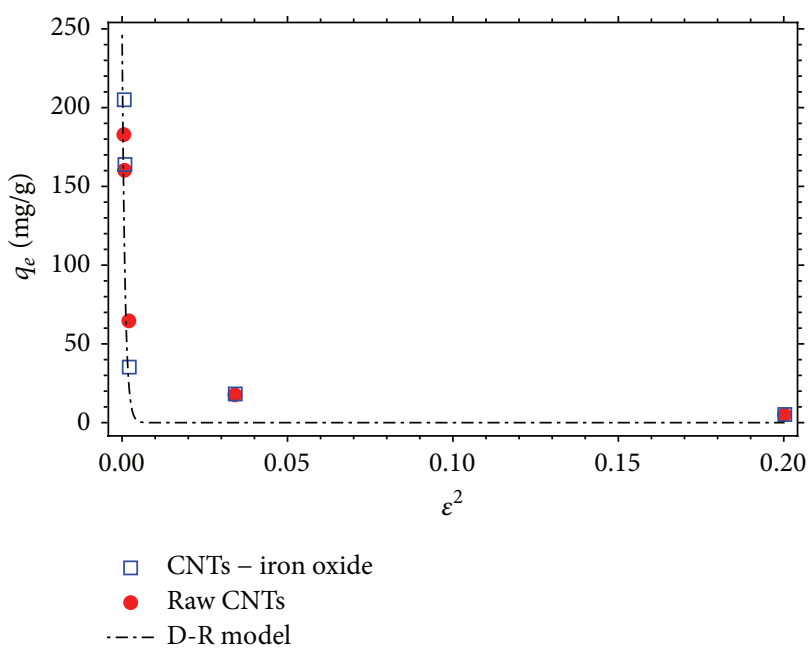

FIGURE 16: Dubinin-Radushkevich adsorption isotherm model fitting with benzene adsorption on raw CNTs and iron oxide impregnated CNTs.

38]. So, here, two main effects are Vander Waals forces and $\pi$ $\pi$ interaction between $\pi$-electrons of CNTs and benzene ring.

\section{Conclusion}

Raw and iron oxide nanoparticles impregnated CNTs were used for the adsorptive removal of benzene from water. The maximum removal by raw and iron oxide impregnated CNTs under these experimental conditions was 53 and 61\%, respectively. From kinetic study, it was found that pseudo-firstorder model best fits the experimental data for adsorption of benzene from water. Initial concentration of benzene was varied from 1 to $200 \mathrm{mg} / \mathrm{L}$. Langmuir isotherm model was found to give better fit with adsorption data. Iron oxide impregnated CNTs showed higher adsorption capacity of $987.58 \mathrm{mg} / \mathrm{g}$ than raw CNTs, which showed adsorption capacity of $517.27 \mathrm{mg} / \mathrm{g}$, under the same experimental conditions. $\mathrm{D}-\mathrm{R}$ model provided information about physical adsorption 
of benzene on CNTs. Values of adsorption energy calculated using D-R model were $0.027 \mathrm{~kJ} /$ mole for raw CNTs and $0.021 \mathrm{~kJ} /$ mole for iron oxide impregnated CNTs, indicating physical adsorption of benzene.

\section{Conflict of Interests}

The authors declare that there is no conflict of interests regarding the publication of this paper.

\section{Acknowledgment}

The authors would like to acknowledge the support provided by the Department of Chemical Engineering, King Fahd University of Petroleum and Minerals, Saudi Arabia.

\section{References}

[1] J. A. Kent, Kent and Riegel's Handbook of Industrial Chemistry and Biotechnology, vol. 1, Springer Science \& Business Media, 2010, http://books.google.com/books?id=AYjFoLCNHYUC\& pgis $=1$.

[2] C. Kent, Basics of Toxicology, vol. 3 of Preserving the Legacy, John Wiley \& Sons, New York, NY, USA, 1998, http://books .google.com/books?id=VEUlWz4vQssC\&pgis=1.

[3] J. J. McKetta Jr., Encyclopedia of Chemical Processing and Design: Volume 67-Water and Wastewater Treatment: Protective Coating Systems to Zeolite, CRC Press, 1999, http://books.google .com/books?id=uDuCw37SaUMC\&pgis=1.

[4] N. Wibowo, L. Setyadhi, D. Wibowo, J. Setiawan, and S. Ismadji, "Adsorption of benzene and toluene from aqueous solutions onto activated carbon and its acid and heat treated forms: influence of surface chemistry on adsorption," Journal of Hazardous Materials, vol. 146, no. 1-2, pp. 237-242, 2007.

[5] B. A. Abussaud, N. Ulkem, D. Berk, and G. J. Kubes, "Wet air oxidation of benzene," Industrial and Engineering Chemistry Research, vol. 47, no. 13, pp. 4325-4331, 2008.

[6] K. Kabra, R. Chaudhary, and R. L. Sawhney, "Treatment of hazardous organic and inorganic compounds through aqueousphase photocatalysis: a review," Industrial and Engineering Chemistry Research, vol. 43, no. 24, pp. 7683-7696, 2004.

[7] X. Liu, M. Wang, S. Zhang, and B. Pan, "Application potential of carbon nanotubes in water treatment: a review," Journal of Environmental Sciences, vol. 25, no. 7, pp. 1263-1280, 2013.

[8] S. Iijima, "Helical microtubules of graphitic carbon," Nature, vol. 354, no. 6348, pp. 56-58, 1991.

[9] X. Ren, C. Chen, M. Nagatsu, and X. Wang, "Carbon nanotubes as adsorbents in environmental pollution management: a review," Chemical Engineering Journal, vol. 170, no. 2-3, pp. 395-410, 2011.

[10] S. Agnihotri, J. P. B. Mota, M. Rostam-Abadi, and M. J. Rood, "Adsorption site analysis of impurity embedded single-walled carbon nanotube bundles," Carbon, vol. 44, no. 12, pp. 23762383, 2006.

[11] O. G. Apul and T. Karanfil, "Adsorption of synthetic organic contaminants by carbon nanotubes: a critical review," Water Research, vol. 68, pp. 34-55, 2015.

[12] H. A. Asmaly, B. Abussaud, Ihsanullah et al., "Evaluation of micro- and nano-carbon-based adsorbents for the removal of phenol from aqueous solutions," Toxicological \& Environmental Chemistry, vol. 97, no. 9, pp. 1164-1179, 2015.
[13] W. Chen, L. Duan, and D. Zhu, "Adsorption of polar and nonpolar organic chemicals to carbon nanotubes," Environmental Science and Technology, vol. 41, no. 24, pp. 8295-8300, 2007.

[14] F. Su, C. Lu, and S. Hu, "Adsorption of benzene, toluene, ethylbenzene and p-xylene by $\mathrm{NaOCl}$-oxidized carbon nanotubes," Colloids and Surfaces A: Physicochemical and Engineering Aspects, vol. 353, no. 1, pp. 83-91, 2010.

[15] F. Yu, J. Ma, and Y. Wu, "Adsorption of toluene, ethylbenzene and xylene isomers on multi-walled carbon nanotubes oxidized by different concentration of $\mathrm{NaOCl}$," Frontiers of Environmental Science and Engineering in China, vol. 6, no. 3, pp. 320-329, 2011.

[16] F. Yu, Y. Wu, X. Li, and J. Ma, "Kinetic and thermodynamic studies of toluene, ethylbenzene, and $m$-xylene adsorption from aqueous solutions onto $\mathrm{KOH}$-activated multiwalled carbon nanotubes," Journal of Agricultural and Food Chemistry, vol. 60, no. 50, pp. 12245-12253, 2012.

[17] A. Zeino, A. Abulkibash, M. Khaled, and M. Atieh, "Bromate removal from water using doped iron nanoparticles on multiwalled carbon nanotubes (CNTS)," Journal of Nanomaterials, vol. 2014, Article ID 561920, 9 pages, 2014.

[18] B. S. Tawabini, S. F. Al-Khaldi, M. M. Khaled, and M. A. Atieh, "Removal of arsenic from water by iron oxide nanoparticles impregnated on carbon nanotubes," Journal of Environmental Science and Health-Part A: Toxic/Hazardous Substances and Environmental Engineering, vol. 46, no. 3, pp. 215-223, 2011.

[19] Ihsanullah, F. A. Al-Khaldi, B. Abu-Sharkh et al., "Effect of acid modification on adsorption of hexavalent chromium $(\mathrm{Cr}(\mathrm{VI}))$ from aqueous solution by activated carbon and carbon nanotubes," Desalination and Water Treatment, vol. 57, no. 16, pp. 7232-7244, 2016.

[20] Ihsanullah, F. A. Al-Khaldi, B. Abusharkh et al., "Adsorptive removal of cadmium(II) ions from liquid phase using acid modified carbon-based adsorbents," Journal of Molecular Liquids, vol. 204, pp. 255-263, 2015.

[21] Ihsanullah, H. A. Asmaly, T. A. Saleh, T. Laoui, V. K. Gupta, and M. A. Atieh, "Enhanced adsorption of phenols from liquids by aluminum oxide/carbon nanotubes: comprehensive study from synthesis to surface properties," Journal of Molecular Liquids, vol. 206, pp. 176-182, 2015.

[22] H. A. Asmaly, B. Abussaud, Ihsanullah, T. A. Saleh, V. K. Gupta, and M. A. Atieh, "Ferric oxide nanoparticles decorated carbon nanotubes and carbon nanofibers: drom synthesis to enhanced removal of phenol," Journal of Saudi Chemical Society, vol. 19, no. 5, pp. 511-520, 2015.

[23] Ihsanullah, A. M. Al Amer, T. Laoui et al., "Fabrication and antifouling behaviour of a carbon nanotube membrane," Materials \& Design, vol. 89, pp. 549-558, 2016.

[24] Ihsanullah, T. Laoui, A. M. Al-Amer et al., "Novel anti-microbial membrane for desalination pretreatment: a silver nanoparticledoped carbon nanotube membrane," Desalination, vol. 376, pp. 82-93, 2015.

[25] F. A. Al-Khaldi, B. Abu-Sharkh, A. M. Abulkibash, and M. A. Atieh, "Cadmium removal by activated carbon, carbon nanotubes, carbon nanofibers, and carbon fly ash: a comparative study," Desalination and Water Treatment, vol. 53, no. 5, pp. 1417-1429, 2015.

[26] B. S. Tawabini, M. A. Atieh, O. Y. Bakather et al., "Removal of chromium (III) from water by using modified and nonmodified carbon nanotubes," Journal of Nanomaterials, vol. 2010, Article ID 232378, 9 pages, 2010. 
[27] S. Zhang, T. Shao, H. S. Kose, and T. Karanfil, "Adsorption kinetics of aromatic compounds on carbon nanotubes and activated carbons," Environmental Toxicology and Chemistry, vol. 31, no. 1, pp. 79-85, 2012.

[28] K. Y. Foo and B. H. Hameed, "Insights into the modeling of adsorption isotherm systems," Chemical Engineering Journal, vol. 156, no. 1, pp. 2-10, 2010.

[29] M. S. Onyango, Y. Kojima, O. Aoyi, E. C. Bernardo, and H. Matsuda, "Adsorption equilibrium modeling and solution chemistry dependence of fluoride removal from water by trivalent-cation-exchanged zeolite F-9," Journal of Colloid and Interface Science, vol. 279, no. 2, pp. 341-350, 2004.

[30] S. S. Tahir and N. Rauf, "Removal of a cationic dye from aqueous solutions by adsorption onto bentonite clay," Chemosphere, vol. 63, no. 11, pp. 1842-1848, 2006.

[31] E. Fortunati, F. D’Angelo, S. Martino, A. Orlacchio, J. M. Kenny, and I. Armentano, "Carbon nanotubes and silver nanoparticles for multifunctional conductive biopolymer composites," Carbon, vol. 49, no. 7, pp. 2370-2379, 2011.

[32] Z.-Z. Zhu, Z. Wang, and H.-L. Li, "Functional multi-walled carbon nanotube/polyaniline composite films as supports of platinum for formic acid electrooxidation," Applied Surface Science, vol. 254, no. 10, pp. 2934-2940, 2008.

[33] Z. Yong, Z. Zhu, Z. Wang, J. Hu, and Q. Pan, "One-dimensional carbon nanotube- $\mathrm{Fe}_{x} \mathrm{C}_{y}$ nanocrystal composite," Nanotechnology, vol. 18, no. 10, Article ID 105602, 2007.

[34] H. Wang, T. B. Shrestha, M. T. Basel et al., "Magnetic$\mathrm{Fe} / \mathrm{Fe}_{3} \mathrm{O}_{4}$-nanoparticle-bound $\mathrm{SN} 38$ as carboxylesterasecleavable prodrug for the delivery to tumors within monocytes/macrophages," Beilstein Journal of Nanotechnology, vol. 3, no. 1, pp. 444-455, 2012.

[35] A. Lancok, M. Klementova, P. Bezdicka, and M. Miglierini, "Characterization of magnetic iron oxide nanoparticles," Hyperfine Interactions, vol. 189, no. 1-3, pp. 97-103, 2009.

[36] V. Gupta and T. A. Saleh, "Syntheses of carbon nanotubemetal oxides composites; adsorption and photo-degradation," in Carbon Nanotubes-From Research to Applications, D. S. Bianco, Ed., chapter 17, InTech, Rijeka, Croatia, 2011.

[37] B. Pan and B. Xing, "Adsorption mechanisms of organic chemicals on carbon nanotubes," Environmental Science and Technology, vol. 42, no. 24, pp. 9005-9013, 2008.

[38] Y. Liu, J. Zhang, X. Chen, J. Zheng, G. Wang, and G. Liang, "Insights into the adsorption of simple benzene derivatives on carbon nanotubes," RSC Advances, vol. 4, no. 101, pp. 5803658046, 2014. 

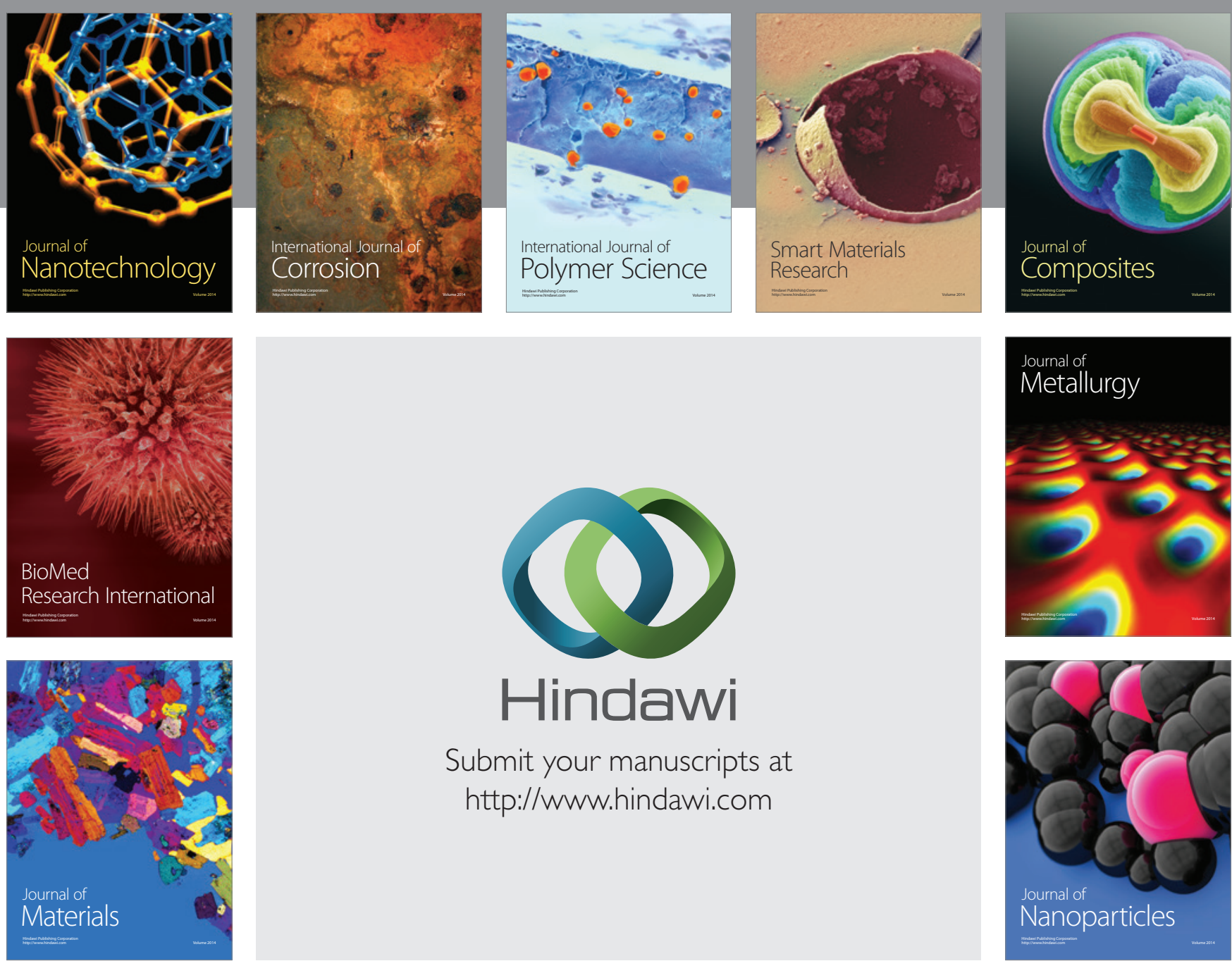

\section{Hindawi}

Submit your manuscripts at

http://www.hindawi.com

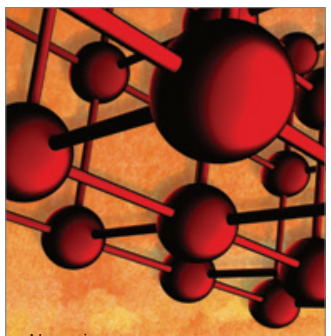

Materials Science and Engineering
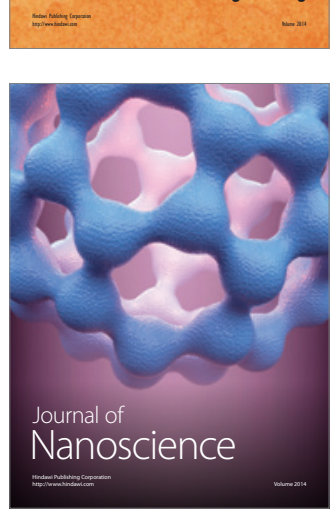
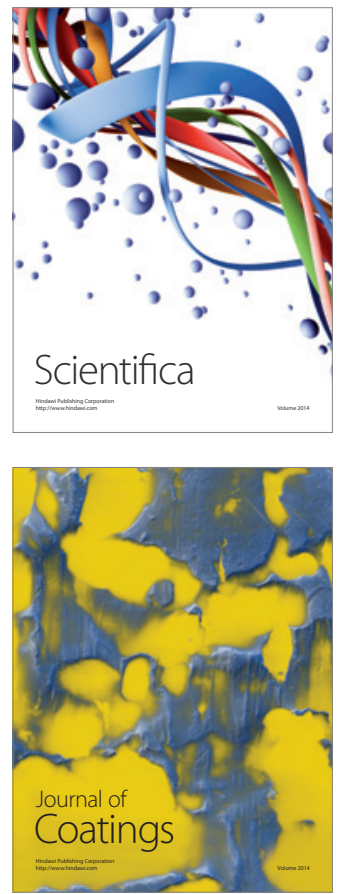
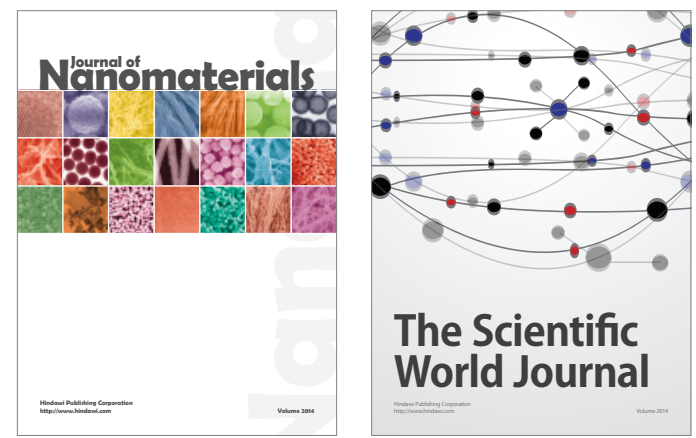

The Scientific World Journal
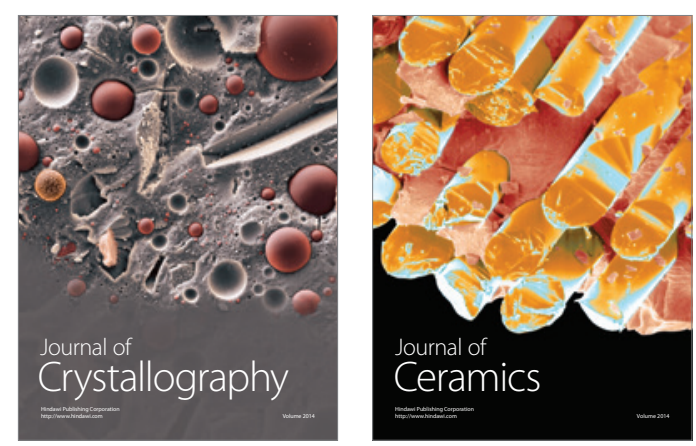
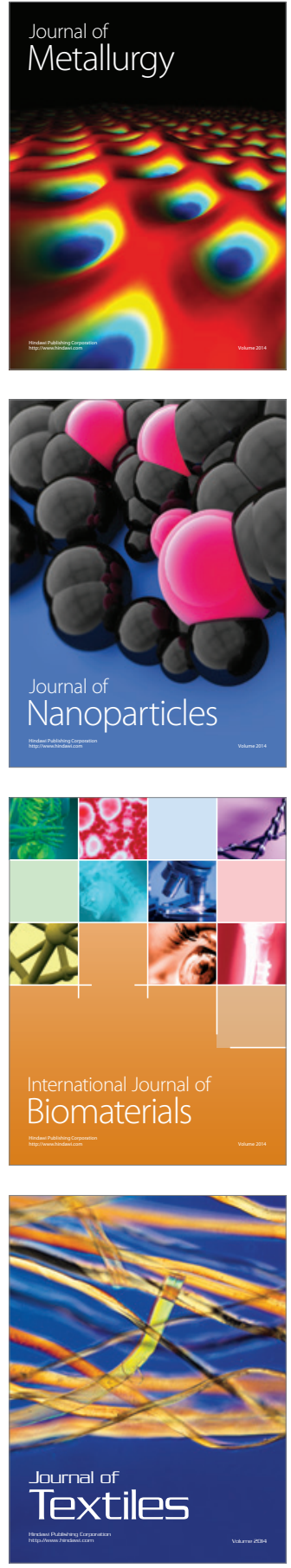